\title{
Canopy walking as a proposal for the açaí harvest in Amazonas
}

\author{
Magnólia Grangeiro Quirino, Patrícia dos Anjos Braga Sá dos Santos², Luiz Guilherme Oliveira Marques3, Karla \\ Mazarelo Maciel Pacheco ${ }^{4}$. \\ 1/2/3/4 Federal University of Amazonas, Department of Design and Graphic Expression. Av. Rodrigo Otávio Jordão Ramos, 3000 - \\ Coroado. \\ North Sector Campus - 69077-000 - Manaus/AM. Brasil
}

\begin{abstract}
This paper is about a proposal of application of canopy walking as a way of optimizing the açai crop process made by "Cooperativa de Açai de Codajás/AM". The cooperative, which operates in all stages of the productive chain of the fruit, faces difficulties ranging from risks imposed to the extractors during the harvest, in addition to disinterest of part of the cooperative young people. In order to understand the scenario of the açai crop, a study was carried out on the geopolitics of the Amazon, from which new forms of understanding the rural space are discussed, as well as the contribution of Sustainable Design to the açai harvest proposal. A field research was made, accompanied by the President of the Cooperative, during which it was detected that the production chain presents a set of improvised and non-systematic actions, evidencing the need for improvements in the way that traditional harvesting is made, in order to make it more secure and attractive to people. The use of the concept of canopy walking has resulted in a proposal that avoids the unsafe escalation in the açai tree and promotes a safe crop of the fruit through a system composed of stairs, catwalks, protective nets and platforms
\end{abstract}

Keywords. Açai harvest; Geopolitics of the State of Amazonas; Sustainable design.

\section{Amazonas Geopolitics}

Amazon is a state of great territorial extension bordering three countries - Colombia, Venezuela and Peru and the states of Roraima, Pará, Mato Grosso, Rondônia and Acre, a fact that exemplifies the complexity and relevance of the theme. The existence of so many borders implies economic transactions combined under different norms, contributing to an internal economic development full of divergences. In an attempt to elucidate this dynamics, the geopolitics of the state of Amazonas is studied, which includes several aspects, among them, the process of population of the state and its economic development.

In the case of Amazon region, settlement is characterized by occupation on the river banks of the Negro, Solimões-Amazonas, Madeira, Purus and Juruá rivers, among others. Attracted by the richness of this basin, the Portuguese and Spanish, in the seventeenth century, occupied the places with the largest indigenous population.

Thus, in order to conquer the territory dominated by the hydrographic basin, the Portuguese made alliances with the Indians who, in turn, built villages. However, according to Machado (1999) such facts were not significant for the urban formation of the region:
Indeed, since colonial times, successive government reports have indicated that selfsufficiency in agricultural holdings, the difficulty of communication, the low availability of labor, and the lack of productive complementarity among the Amazon subspaces were powerful obstacles to the growth of cities. (MACHADO 1999).

Based on this report, it can be seen that, in colonial times, there were difficulties present up to now in this region. The indigenous respond with indifference to the external interventions that are taken to their tribes, indifference that is similar to that of the young participants of the cooperative with respect, a behavior also identified in other segments in the Amazon.

\footnotetext{
a Corresponding author: quirino.designer@gmail.com
} 


\section{New ways of understanding rural areas}

The rural area consists of a geographic space destined to the practice of agricultural activities, extractivism, forestry and environmental conservation. The understanding of rural space has, however, expanded, and today also adds the concept of rural tourism, which in turn suggests new fronts of work and collaborates with the permanence of the population in the countryside, avoiding rural evasion.

Tourism promotes the movement of people to different places of their dwellings, in trips for the purpose of leisure. These trips provide knowledge about the way of living of certain society. At the same time, the tourist carries with him his experience, establishing comparisons between his way of living and the way of life of the place visited.

In this sense, tourism is configured as a learning process, which propagates to all tourism models, including rural tourism. The tourism project in rural areas expands the economy of the region, keeping the population in the countryside and attracting new residents. In the opinion of Elesbão et al. (2014), rural tourism favors local development based on environmental conservation:

Tourism in rural areas is an activity that within the context of the multifunctionality of agriculture can represent an important strategy of local development, enabling the dynamization of rural spaces, the preservation of nature and the emergence of new jobs (ELESBÃO 2014).

A great achievement of rural tourism is to promote the recovery and appreciation of the customs and traditions of rural life. Still according to Elesbão et al., this fact allows the ruralist to add value to rural products and services, evidencing the advantages of rural tourism in the same way that favors the economic sector.

These advantages also extend to social and environmental dimensions, among others. According to Klein (2012, apud ELESBÃO et all 2014), many are the benefits of rural tourism, such as in the social sphere, the possibility of interaction between social extracts and the exchange of experiences; And in the environmental dimension, the preservation of the rural environment and the promotion of environmental education.

In this context, the practice of rural tourism promotes improvements both for tourists and for local actors, albeit in different ways. The tourists, starting from an exercise of otherness, start to value the ruralists and their way of life. While local actors see rural tourism as an endogenous process, understanding their role and their responsibilities to the environment in which they live, and perceive that they are formers of their history, of their culture and responsible for preserving the natural resources that the they surround.

\section{Field Research}

The Açai Cooperative is located in the municipality of Codajás. According to the Institute for Sustainable Agricultural and Forestry Development of the State of Amazonas (IDAM), Codajás is located in the Rio Negro

- Solimões Region. The distance from its municipal headquarters to Manaus is $240 \mathrm{~km}$ (in a straight line), and

$290 \mathrm{~km}$ by waterway. However, the only access to Codajás is by waterway.

The field research was guided by the president of the Cooperativa de Açaí de Codajás, Mrs. Franciani Sobreira da Silva, who took us for a visit to the Cooperativa and the açai plantations.

In the first years of the Cooperative's foundation, there was great productivity, with exports to the United States and Canada in 2006 and 2007. The Superintendence of the Manaus Free Zone - SUFRAMA delivered the building with a physical structure designed to benefit the Açai which corresponds to fruit selection, washing, pulping, pasteurisation, packaging, freezing and transport. In addition to the physical structure, modernized equipment was donated to carry out all the activities, including an ice factory, a truck, a motorized rail, a refrigerated container and a raft. All this venture motivated the economy of the açai in Codajás, causing the municipality to deserve the title of greater producer of açai of the state of the Amazonas. However, this period of economic animosity was short due to several factors, including operational, administrative and financial difficulties.

\section{Problems of the Cooperativa de Açaí de Codajás}

Today the Cooperativa works with machines that need maintenance and, for this reason, are deactivated. In 2009, cooperatives took over the financial management of the Cooperativa, however, several obstacles hampered the commercialization of açai production. Today, the Cooperativa tries to recover old customers and get new buyers for the fruit, but the president says they find it difficult to reverse this situation, besides the lack of maintenance in the building and equipment.

There is a lack of interest on part of the Cooperativa workers to assume activities and responsibilities in addition to the extractive work, which occurs exclusively during the harvest period. As pointed out by the president of the Cooperativa, they refuse to perform other activities that would also fall within their competence, such as those of an administrative and financial nature. During the offseason, cooperatives seek other income-generating activities, leaving the place deactivated during this period. 
Another difficulty pointed out by the president is the absence of interest of the young people for the açai tradition, which contributes to a rural exodus, aggravated by the culture of assistance that, unconsciously or not, leads people to settle in the hope of improvements promoted by the government. This behavior was reported in the process of urbanization of the State of Amazonas and has been reproduced in the present day.

\section{Açaí crop description}

The Work journey in the field begins at six o'clock in the morning, before that time the woods are still dark, and the activities are finished at seventeen and thirty. Daily, two to three bags of fifty kilos of açai are collected (approximate quantity per person). The harvesting of the fruit is carried out in a traditional way and devoid of equipment to speed up and facilitate the tasks, as well as without Personal Protective Equipment (PPE). In summary, it is an activity carried out in a rustic and dangerous manner, requiring the physical effort of the extractivist worker.

In the Amazon, the harvest lasts from January to August, although variations of the months may occur in the other açai producing states. Extraction of the clusters includes climbing on the stipe, aided by an artifact made of fibers called peconha (Figure 1) that is tied to the feet of the harvester. With the peconha in the feet and a knife in the hands of the extractivist worker, the curls are cut from the palm tree and placed on the ground.

The harvest is performed by young climbers and boys. The ability of climbers is highly valued by the extractive community, and this practice, although dangerous, is part of the tradition and culture of açaí.

Climbing the palm trees using only the pecuniary points some risks to the extractivist worker. Although the pecuni is made of vegetable fiber (Figure 1) that has a reasonable resistance able to support the weight of the climber, it does not guarantee the safety of the same, as it is possible these fibers to break and cause serious accidents.
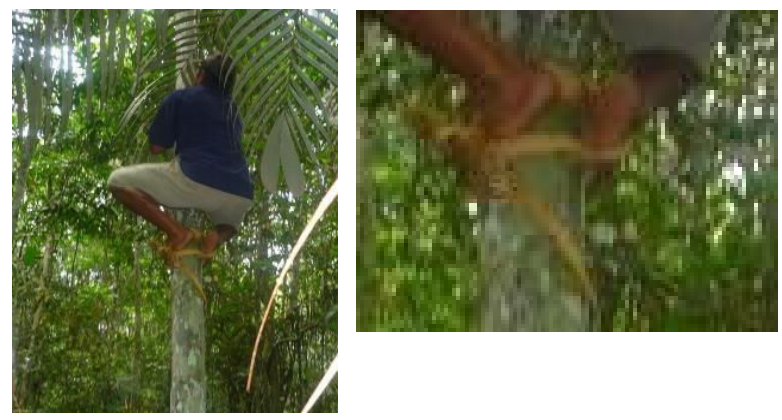

Figure 1. Removal of açai bunches with the use of "peconha". Detail of the "peconha".

Fonte - http://fas-amazonas.org/2010/08/fas-lanca-projetode- desenvolvimento-de-turismo-comunitario-noamazonas.
In the climbing of the palms, the comments of the collectors about ants stings and scratches in the body are frequent. Another recurrent report concerns the difficulty of detecting the ripening of the fruits, before climbing the palm tree, when they are still in the soil. This difficulty is caused by two factors: 1) The distance between the collector and the bunches is approximately

10 meters, due to the height of the palms that vary between $12 \mathrm{~m}$ to $20 \mathrm{~m}$. This distance is a major deterrent to determining if the fruit is ripe. 2) the low luminosity in the forest, where the crowns of the trees are great covering a part of the fruits, hindering the visibility, Situation aggravated by the shade made by the treetops.

In this scenario, palm climbing represents a good opportunity for the Sustainable Design intervention, considering that the venom, although an integral part of the açai extractive communities' tradition, is an unsafe artifact for the workers.

Pazmino (2007) states that sustainable design is comprehensive and complex. In its understanding, sustainable design encompasses environmental, economic and social welfare goals, proposing the responsibility not to undermine the current environmental balance and to ensure this balance for future generations.

A crise ambiental que estamos vivendo no momento atual leva o design a assumir uma postura em que os princípios da sustentabilidade façam parte intrinsecamente do seu conjunto de estratégias.

The idea of well-being is a social construction that forms over time, according to a variety of factors. The idea of welfare that is now dominant in the West and widely spread throughout the world was born with the industrial revolution. (Manzini, 2008)

From Manzini's speech, it can be observed that there is a relationship between the idea of wellbeing and the industry. The industrial system relates the concept of well-being to the condition of having industrialized products. This industrial model motivated by the increase of productivity generates a mechanism that strengthens the consumption.

Consumption strengthens industry, on the other hand, weakens the environment. Industrial strengthening involves the excessive extraction of natural resources and does not diminish the possibility of finite resources. It is foolish to admit consumption as the only alternative to well-being and to neglect its impacts on the environment.

In this sense, the idea of well-being, defined as a result of the possession of objects, needs to be reevaluated to discuss the adversities of consumption and its implications, so that it is possible to configure other possibilities. Sustainable design proposes new models of consumption and production that point out other paths beyond the frontier of consumption and enjoying the sharing of objects. These new models require of the industrial system a new direction, which requires an educational process. 
As is well known, the industrial system has a complex structure, strengthened by several social actors that will react adversely with the implementation of the new models of consumption and production. This work shows signs of laborious activity, but it is not impossible.

\section{Case study}

Some equipment used to harvest the açai were collected in the literature, for the study of case, which will be described separately.

The first equipment is a rustic açai harvesting device (Figure 2). According to Homma (2006), the artifact is made of wood and at its end there is a piece of iron rebar that removes the bunch of the palm tree.

The equipment shown in the photos is authored by Mr. Dorival Costa Carvalho, who lives in the Municipality of Marabá - PA. The versions of the equipment, with variations in the cutting system and the use of materials, illustrate well the local technical knowhow.

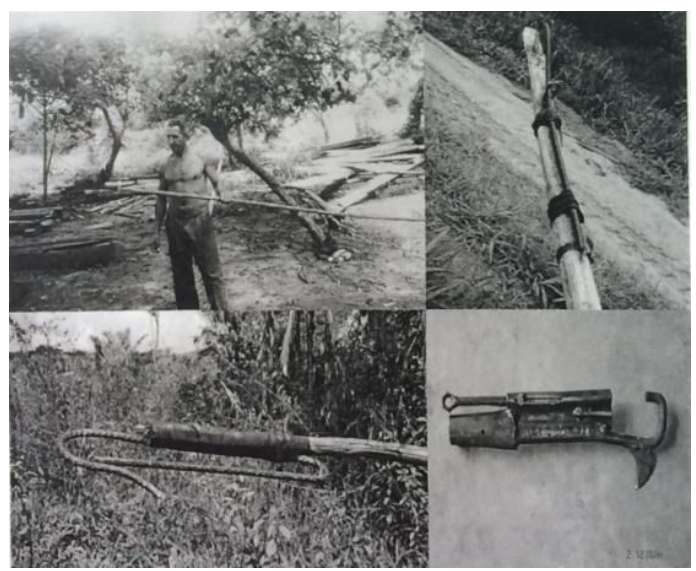

Figure 2. Açai bunch collector made of wood with its variations in the cutting system.

Fonte: Homma (2006).

The second equipment is the açai "picker" prototype (Figure 3 ). The equipment is included in the Activity Report made by the Amazonas Sustainable Foundation - FAS (2014). FAS executed a project for the açai productive chain that resulted in this prototype. A device which is fixed to the palm tree, slid by means of a pulley system having a guillotine cutting the cluster, and then ropes that descend to the ground attach the same.

Such equipment has advantages as it reduces physical stress; Prevents the climbing of the palm tree, consequently providing security; And increases the removal of curls. There are, however, complicating aspects in this prototype, such as the difficulty of fixing the equipment in the açai palm, added to the ineffectiveness of the guillotine in the cut.

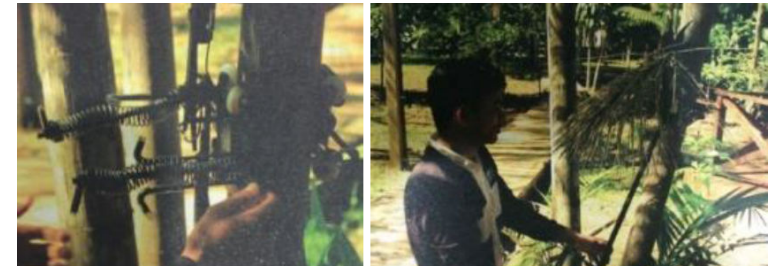

Figure 3. Açai "picker" prototype.

Fonte - 2014 Fundação Amazonas Sustentável - FAS Activities Report.

The third identified equipment focuses on a conceptual proposal in patent registration. In the Invention Patent Description Report, the apparatus is defined as: "Equipment and Methods for Harvesting Fruit Bunches" (PI 0803992-5) (Figure 4). In the report, the equipment is presented as a tool for harvesting bunches of fruit in general. The equipment consists of an aluminum rod of adjustable size up to approximately 12 meters in length. At its upper end, there is a bunch cutting system, a movable receptacle for receiving the bunch and pulleys which enable the bundle to descend.
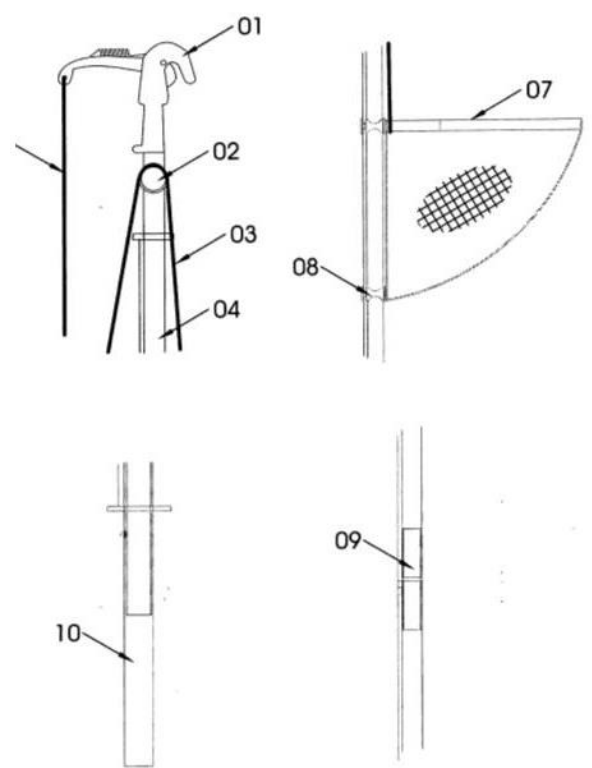

Figure 4. Equipment and Methods for Harvesting Fruit Bunches. Fonte - Relatório descritivo de Patente de invenção (PI 0803992-5).

This equipment offers advantages both for the quality of the fruit and for the safety of the climber. In terms of fruit quality, two activities can be mentioned: the selective cutting of the bunch and its controlled descent, avoiding its contact with the soil. In this way, the contamination with the existing residues in the soil is prevented and the fruits are allowed to remain in the ráquilas and not to spread in the soil, therefore, a greater use of the fruits.

Another advantage is the increase of the withdrawal of curls, which means greater productivity without risks to the collector.

As for safety, the equipment avoids palm climbing and direct contact with sharp instruments. This 
equipment performs the function of an EPI. Another favorable item is the technical feasibility of low complexity and ease of use.

\section{Proposal for the harvest of açaí: the Canopy walking}

However, our proposal sought another way of approaching the issue. We did not present the development of equipment for harvesting the açai bunches, but rather a proposal to avoid climbing the açai tree and to promote the safe collection: canopy walking. Canopy walking (Figure 5) consists of ladder, walkways with protective net and platforms. In the platforms will be inserted a system of pulleys fixed in the bunches to descend them to the ground.
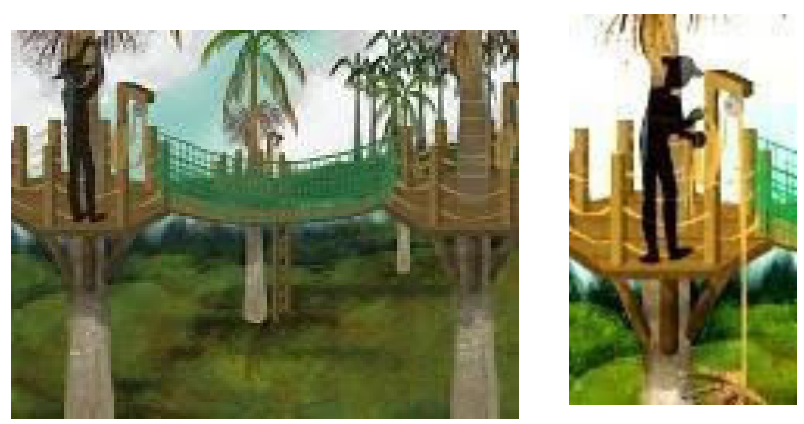

Figure 5. Canopy walking with a system of sheaves as proposal for the harvest of the acai.

Canopy walking is a radical sport that consists of crossing between platforms set high in the trees, overcoming different types of obstacles like stairs and suspended bridges. The canopy has been used for leisure, recreation and studies of fauna and flora. In it suspended bridges are built in the treetops without damaging them, taking care to preserve the environment. In our proposal we intend to extend the use of canopy to the extractive activity of açaí. In this way, we propose the construction of a structure for the practice of canopy walking in the açai plantation that will be permanently mounted, serving for the açai harvest by the extractivist worker in the harvest period, and for rural tourism during the off season.

In the context of sustainable design, Margolin (2014) identifies the expansion of ecotourism and cultural tourism as welcome practices. Themes currently under way that bring the economy and the environment closer together.

In the opinion of Elesbão et al. (2014), rural tourism means a local development strategy that favors environmental conservation. The author points out as benefits of rural tourism the dynamism of rural space and the emergence of new jobs. In this sense, dynamizing the rural space means implementing an activity in the off season, an inactive period in the açai plantation, which can be transformed by the new activity, with demand for new jobs.
In the specific case for the Cooperativa de Açai de Codajás, the proposal of a canopy tree seeks to overcome three problems: the climbing of the açai, the harvest of the açai and the stagnation of the activities during the off season. As well as, attract young cooperatives to the harvest.

Our proposal provides for the setting up of a permanent structure that meets the harvest and offseason periods. As today in the off-season extractive activities are paralyzed, it would be interesting to make use of the structure for playful, educational, sporting and profitable activities for the Cooperativa. Therefore we present an alternative of canopy walking combined with a ladder. The structure will be constructed with panels produced with the acai seeds, which will be detailed later, and will have two purposes: to facilitate the access to the palm fronds in the extractive activity and to allow the sports practice, which attracts people to the tourism.

Canopy walking, as an optimization alternative, includes platforms on the açai trees and walkways that allow access between the palm trees. The extractivist worker will reach the top of the palm tree through the ladder, will settle on the platform, cut the açai bunch and descend it by means of a rope. You will then cross the catwalk to another platform and perform the removal of another bunch. This activity can be performed safely and more agile.

The introduction of connections between açai trees and ladders and pulley systems will facilitate the escalation of the extractivist worker during the harvest season and will result in a structure for sports practice during the off-season, in which the activities of the Cooperativa are paralyzed.

The arboreal will provide the extractivist worker with greater security for the climbing in the açai tree and efficiency in the collection of the bunches avoiding loss of fruits. In each palm tree there will be a platform in which there is a system of pulleys fixed in the bunches of açai to descend them to the ground.

Canopy walking favors the safety and health of the extractivist worker, reducing their physical effort and the time needed to access the açai bunches. In this way, it allows the removal of a greater number of bunches per açai palm, resulting in an improvement in the yield of the açai crop. Thus, canopy walking will have intense use both during the harvest and in the off season.

Canopy walking aims to favor the harvest of the açai during the period of the harvest and to dynamize the region in the period of the off-season, with the rural tourism.

\section{Conclusion}

It is believed that the rural and cultural tourism complex is an alternative of generating work in the countryside and could arouse the interest of the young people of Codajás and thus, in a first moment, the evasion of young people of the municipality. In a second moment, it 
is intended to extend this interest to the productive activities of the açaí. In this sense, the solution presented for a technical problem ends up being also adequate to two problems of a cultural nature, which is the lack of interest of the young people and the paralysis of the activities in the off-season period.

The article reports a topic still little explored in the literature, regarding the development of a proposal for the açai crop in the State of Amazonas. This study is a punctual search to indicate improvements to the harvest that represents an unhealthy activity and with signs of danger. Another problem discussed was the paralysis of activities that became unproductive for the Cooperativa de Açaí de Codajás.

For the realization of this proposal for the açai harvest, a theoretical survey was made regarding the design and its interface with sustainability. As a background for this discussion, concepts such as: Sustainable Design, the Geopolitics of the State of Amazonas and New Forms of Understanding of the Rural Area.

\section{REFERENCES}

ELESBÃO, Ivo; SOUZA, Marcelino de; KLEIN, Ângela Luciane.Temáticas emergentes em Turismo Rural. Funções educativas do turismo rural pedagógico: o Projeto "Turismo Rural e Escola - Fazendo Eco" no Distrito Federal. São Paulo. 2014.

HOMMA, Alfredo Kingo Oyama. Sistema de Produção do Açaí (Colheita e pós-colheita). Embrapa Amazônia Oriental; Sistemas de Produção; Num. 04; ISSN18094325 Versão Eletrônica; Belém, PA; Dezembro, 2006.

MACHADO, Lia Osório. Urbanização e mercado de trabalho na Amazônia Brasileira. Cadernos IPPUR.1999.

MANZINI, Ezio. Design para a inovação social e sustentável: comunidades criativas, organizações colaborativas e novas redes projetuais. Rio de Janeiro: Epapers, 2008. (Cadernos do Grupo de Altos Estudos; v. $1)$.

MARGOLIN, Victor. Políticas do artificial: ensaios e estudos sobre o design. Editora José Olympio LTDA. Rio de Janeiro. 2014.

PAZMINO, Ana Verónica. Uma reflexão sobre Design Social, Eco Design e Design Sustentável. I Simpósio Brasileiro de Design Sustentável. Curitiba, Paraná, 2007.
QUIRINO. Magnólia Grangeiro. Uma proposta de modelo conceitual para a produção do açaí no Estado do Amazonas. Tese de doutorado. Universidade Federal do Amazonas. 2016. 